\title{
CIRJE-F-553 \\ Interregional Tax Competition and \\ Intraregional Political Competition: \\ The Optimal Provision of Public Goods
}

Toshihiro Ihori

University of Tokyo

C. C. Yang

National Chengchi University

April 2008

CIRJE Discussion Papers can be downloaded without charge from:

http://www.e.u-tokyo.ac.jp/cirje/research/03research02dp.html

Discussion Papers are a series of manuscripts in their draft form. They are not intended for circulation or distribution except as indicated by the author. For that reason Discussion Papers may not be reproduced or distributed without the written consent of the author. 


\title{
Interregional Tax Competition and Intraregional Political Competition: The Optimal Provision of Public Goods
}

\author{
Toshihiro Ihori* \\ Department of Economics, University of Tokyo \\ C.C. Yang** \\ Institute of Economics, Academia Sinica \\ Department of Public Finance, National Chengchi University
}

March 2008

\begin{abstract}
[Abstract] This paper explores the implications of the interaction between interregional tax competition and intraregional political competition for the optimal provision of public goods. In contrast to Hoyt's (1991) finding that the extent to which public goods are undersupplied is monotonically increasing in the number of competing regions, we show that the relationship between the level of public good supply and the number of competing regions is nonmonotonic if political as well as tax competition is considered. Interestingly, some certain interaction between interregional tax competition and intraregional political competition can result in the optimal provision of public goods.
\end{abstract}

JEL classification: D72; F20; H41; H71

Key words: Tax competition; Political competition; Public goods

\footnotetext{
* Department of Economics, University of Tokyo, Hongo, Tokyo 113-0033, Japan.

E-mail: ihori@e.u-tokyo.ac.jp

** Corresponding author, Institute of Economics, Academia Sinica, Nankang, Taipei 115, Taiwan.

E-mail: ccyang@econ.sinica.edu.tw

Earlier versions were presented at University of California, Irvine, University of Busan, and the Public Choice Meetings in San Antonio. We would like to thank Ami Glazer, Marty McGuire, Ray Batina, Joosung Jun, Genevieve Tellier, and other participants for their helpful comments.
} 


\section{Introduction}

Competition can be economic or political in nature. Economics tends to focus on the economic competition, while political science tends to focus on the political competition. Either focus alone may be incomplete, if not misleading.

Policy-makers are selected by voters via political competition between citizen candidates. This form of representative democracy is prevalent in the real world. Osborne and Slivinski (1996) and Besley and Coate (1997) emphasize the importance of this political competition, since citizen candidates who possess different policy preferences will implement different policies once selected to become policy-makers. In this paper we incorporate the stylized form of political competition into the stylized model of tax competition. Our focus is on the implications of the interaction between interregional tax competition and intraregional political competition for the optimal provision of public goods. This focus echoes Frey and Eichenberger's (1996) emphasis that both economic and political distortions should be considered in the analysis of tax competition.

A fundamental result in the literature on tax competition is that interregional tax competition for mobile capital generates fiscal externalities and tends to result in an undersupply of public goods in a region. This result is originally articulated by Oates (1972) and formally modeled by Wilson (1986) and Zodrow and Mieszkowski (1986). ${ }^{1}$ In an important contribution, Hoyt (1991) shows that the extent to which public goods are undersupplied is monotonically increasing in the number of competing regions. In contrast to this monotonic finding, we show that the relationship between the level of public good supply and the number of competing regions is non-monotonic if political as well as tax competition is considered. Interestingly, some certain interaction between interregional tax competition and intraregional political competition can result in the optimal provision of public goods.

On the basis of his finding, Hoyt (1991, p. 130) concludes:

\footnotetext{
${ }^{1}$ See Wilson (1999), Wilson and Wildasin (2004), and Fuest et al. (2005) for surveys of the literature.
} 
The existence of wasteful tax competition suggests that the optimal number of jurisdictions is one, thereby eliminating the externalities created by capital taxation. The traditional Tiebout literature argues that having many independent jurisdictions promotes efficiency and taste stratification by increasing the competition among jurisdictions. Thus, a tradeoff is faced, more jurisdictions increase the sorting of residents but at a cost of decreasing the public service provision because of tax competition.

The tradeoff suggested may not exist once political as well as tax competition is considered.

The literature on tax competition for mobile factors largely leaves out the stylized form of political competition as emphasized in this paper. ${ }^{2}$ Persson and Tabellini (1992) is a notable exception, but their focus is not on the provision of public goods. In the presence of tax competition, Edwards and Keen (1996) and Rauscher (1998) consider Leviathan models while Wilson (2005) considers a self-interested-government-official model. These papers take into account some elements of politics within a region, but they do not touch on the selection of policy-makers in a representative democracy.

There are two studies that are most related to our paper. Brueckner (2001) considers a model in which both tax and political competition are present, and individuals are heterogeneous with respect to their valuation of public goods. He shows that, due to the voters' strategic delegation, capital tax rates under tax coordination may be lower than those under tax competition. Fuest and Huber (2001) compare tax competition with tax coordination in a median-voter model. They find that there may be an overprovision of public goods under tax competition and that tax coordination need not be welfare-improving. Although all consider tax and political competition in a framework, there are two main differences in modeling between our paper and these two papers. First, the number of competing regions is fixed at two (a two-country model) in Brueckner (2001), and at infinity (a small-country model) in Fuest and Huber (2001). As a result, the degree of tax competition (i.e., variations in the number of regions) plays no role in both papers. By contrast, the degree

\footnotetext{
${ }^{2}$ For surveys of political economy approaches to tax competition, see Wilson (1999) and Fuest et al. (2005).
} 
of tax competition is the key focus of our paper. Secondly, individual heterogeneity is with respect to the valuation of public goods in Brueckner (2001), and with respect to the effective time endowment in Fuest and Huber (2001). By contrast, individual heterogeneity is with respect to the capital ownership in our paper.

The remainder of the paper is organized as follows. Section 2 presents our model. Section 3 exposes the connection between political competition and tax policy, and Section 4 explores the implications of tax-cum-political competition. Section 5 concludes.

\section{Economy with tax competition}

Our model of the economy is standard in the tax competition literature, ${ }^{3}$ except for the extension from homogeneous to heterogeneous individuals.

Consider an economy in which there are $n$ identical regions, where $n \in\{1, \ldots, \infty\}$. Each region is inhabited by $N$ individuals. There are two factors of production: an interregional immobile factor and a perfectly mobile factor. We will refer to the former as "land" and to the latter as "capital." Each individual in each region has the same claim to land, but unequal claims to capital. Specifically, individual $j$ in region $i$ supplies $\theta \equiv 1 / N$ units of land and $\bar{k}_{i j}$ units of capital.

Let $\bar{k}_{i}=\sum_{j} \bar{k}_{i j}$. Denoting the amount of capital employed in region $i$ by $k_{i}$, capital market clearing requires

$$
\sum_{i} k_{i}=\sum_{i} \bar{k}_{i} \text {. }
$$

All regions produce a single private good whose price is normalized to unity. This private good can either be consumed directly as a private commodity, $c$, or be used to provide the

\footnotetext{
${ }^{3}$ The model is built on Hoyt (1991). As noted by Hoyt, his model follows that of Wildasin (1988). It is a textbook, workhorse model of tax competition; see, for example, Wellisch (2000, Section 4.1) and Haufler (2001, Section 4.3).

${ }^{4}$ "Capital” can be human as well as physical capital.
} 
regional public service, $g .{ }^{5}$ One unit of the private good produces one unit of the public service. The production in each region is given by $f\left(k_{i}\right)$ with $f^{\prime}\left(k_{i}\right)>0$ and $f^{\prime \prime}\left(k_{i}\right)<0$, where a unit of the land input in the region is suppressed. All markets are assumed to be perfectly competitive.

Each region levies a source tax at rate $t_{i}$ on each unit of capital employed within its region. Perfectly mobile capital implies

$$
f^{\prime}\left(k_{i}\right)-t_{i}=r\left(t_{1}, \ldots, t_{n}\right) \forall i
$$

where $r$ is the after-tax rate of return on capital, which depends on $t_{1}, \ldots, t_{n}$ and is equalized across the economy. Using (1)-(2) and the assumption that all regions are identical, we have ${ }^{6}$

$$
\begin{aligned}
& \frac{\partial r}{\partial t_{i}}=\frac{-1}{n} \forall i \\
& \frac{\partial k_{i}}{\partial t_{i}}=\frac{1-(1 / n)}{f^{\prime \prime}\left(k_{i}\right)} \forall i \\
& \frac{\partial k_{i}}{\partial t_{-i}}=\frac{-(1 / n)}{f^{\prime \prime}\left(k_{i}\right)} \forall i,-i
\end{aligned}
$$

where $-i$ denotes any region other than region $i$.

Let $u_{i j} \equiv u\left(c_{i j}, g_{i}\right)$ denote the preferences of individual $j$ in region $i$ over the private good $c$ and the public service $g$. We shall work with the quasi-linear form: $u\left(c_{i j}, g_{i}\right)=c_{i j}+v\left(g_{i}\right)$ with $v^{\prime}>0, v^{\prime \prime}<0$, and $\lim _{g_{i} \rightarrow 0} v\left(g_{i}\right) \rightarrow-\infty$. For one thing, this form has become standard in the literature on public goods. ${ }^{7}$ Perhaps more importantly, the quasilinear form makes our work directly comparable with a large tax competition literature on the efficiency problems associated with the provision of public goods. It is known that the criterion of Pareto efficiency (i.e., the so-called Samuelson condition) alone is unable to

\footnotetext{
${ }^{5}$ The public service may be interpreted as either a publicly provided private good shared equally by all residents or a Samuelson public good consumed jointly by all residents, and there are no spillover effects across regions (see Wilson 1986 and Zodrow and Mieszkowski 1986).

${ }^{6}$ See Hoyt (1991).

${ }^{7}$ See, for example, Besley and Coate (2003) and Batina and Ihori (2005).
} 
uniquely determine the optimal level of public goods in general when individuals are heterogeneous. ${ }^{8}$ A social welfare function is typically introduced to pin it down in such situations. However, this approach may be arbitrary in our context since different social welfare functions as a rule point to different optimal levels of public goods. The advantage of the quasi-linear form is that it enables us to stick to the criterion of Pareto efficiency and, at the same time, uniquely determine the optimal level of public goods even in the case of heterogeneous people.

The government budget constraint in each region implies

$$
g_{i}=t_{i} k_{i} \forall i \text {. }
$$

On the other hand, the individual budget constraint implies

$$
c_{i j}=\theta\left[f\left(k_{i}\right)-\left(r+t_{i}\right) k_{i}\right]+r \bar{k}_{i j} \forall i j
$$

where $f\left(k_{i}\right)-\left(r+t_{i}\right) k_{i}$ is the rent per unit of land in region $i$. By assumption, individual $j$ in region $i$ supplies $\theta$ units of land and $\bar{k}_{i j}$ units of capital.

\section{Political competition and tax policy}

This section analyzes the endogenous formation of the capital tax rate within each region.

We apply the citizen-candidate model proposed by Osborne and Slivinski (1996) and Besley and Coate (1997). More specifically, we consider a two-stage game as in Besley and Coate (2003). First, elections in each region determine which individual is selected to govern the region. Second, tax policies are chosen simultaneously by the elected individuals in the economy. Following Osborne and Slivinski (1996), the political process of selecting a policymaker is viewed as the "political competition" in our model.

We solve the game backward.

\footnotetext{
${ }^{8}$ See Varian (1992, p. 419)
} 


\subsection{Second stage: tax competition}

Let the elected individual in region $i$ own $\bar{k}_{i j}$ units of capital. Given $t_{1}, \ldots, t_{i-1}, t_{i+1}, \ldots t_{n}$, the chosen tax policy $t_{i}$ satisfies

$$
t_{i}\left(\bar{k}_{i j}\right)=\arg \max _{t_{i}}\left\{c_{i j}+v\left(g_{i}\right)\right\} \quad \forall i
$$

where $g_{i}$ and $c_{i j}$ follow (4) and (5), respectively. The first-order conditions for the above program are given by

$$
\frac{\partial u_{i j}}{\partial t_{i}}=\frac{\partial c_{i j}}{\partial t_{i}}+v^{\prime}\left(g_{i}\right) \frac{\partial g_{i}}{\partial t_{i}}=0 \forall i
$$

where $v^{\prime}\left(g_{i}\right)$ is the marginal benefit of the public service. It is assumed that $\partial^{2} u_{i j} / \partial t_{i}{ }^{2}<0$ so that the second-order conditions are met and there is a unique $t_{i}\left(\bar{k}_{i j}\right)$ satisfying (6). ${ }^{9}$

Using (3) and that $k_{i}=\bar{k}_{i}$ in a symmetric Nash equilibrium, (6) leads to

$$
v^{\prime}\left(g_{i}\right)=\frac{(1 / n) s_{i j}+[1-(1 / n)] \theta}{1-[1-(1 / n)] \tau_{i} \varepsilon_{i}} \forall i
$$

where $s_{i j} \equiv \bar{k}_{i j} / \bar{k}_{i}$ (the share of capital owned by individual $j$ in region $\left.i\right), \tau_{i} \equiv t_{i} /\left(r+t_{i}\right)$ (the ad valorem tax rate in region $i)$, and $\varepsilon_{i} \equiv-\left[\partial k_{i} / \partial\left(r+t_{i}\right)\right]\left[\left(r+t_{i}\right) / k_{i}\right]$ (the elasticity of demand for capital with respect to the before-tax rate of return in region $i$ ). The left-hand side (LHS) of (7) denotes the marginal benefit of raising $g_{i}$, while the right-hand side (RHS) refers to the corresponding marginal cost. The term $(1 / n) s_{i j}$ corresponds to the marginal cost of a decrease in the after-tax rate of capital return $r$ due to an increase in $t_{i}$, while the term

${ }^{9} \partial^{2} u_{i j} / \partial t_{i}{ }^{2}<0$ is equivalent to $-\theta(1-(1 / n))\left(\partial k_{i} / \partial t_{i}\right)+v^{\prime}\left(g_{i}\right)\left(\partial^{2} g_{i} / \partial t_{i}{ }^{2}\right)+v^{\prime \prime}\left(g_{i}\right)\left(\partial g_{i} / \partial t_{i}\right)^{2}<0$. A sufficient condition to uphold the inequality is that: (i) $\partial^{2} g_{i} / \partial t_{i}{ }^{2}<0$, which is a standard assumption imposed on the Laffer curve, and (ii) $N$ is large so that $\theta=1 / N$ is small. 
$[1-(1 / n)] \theta$ corresponds to the marginal cost of a decrease in the rent due to an increase in $t_{i}$. As to the denominator of (7), it captures the marginal cost associated with a tax induced outflow of capital.

\section{Special cases}

Condition (7) gives rise to several special cases:

(i) $s_{i j}=\theta$

This represents the case where individuals have the same claim to capital in each region. Then (7) reduces to

$$
N \cdot v^{\prime}\left(g_{i}\right)=\frac{1}{1-[1-(1 / n)] \tau_{i} \varepsilon_{i}} \forall i
$$

which is the standard public-good-provision condition in the presence of tax competition when individuals are homogeneous (see, for example, Wilson and Wildasin, 2004, Eq. (1)).

(ii) $n \rightarrow \infty$

This implies that $\partial r / \partial t_{i} \rightarrow 0$ from (3). Thus, it represents the "price-taker" or "small region” case where the after-tax rate of return on capital is beyond the control of individual regions. Then (7) reduces to

$$
N \cdot v^{\prime}\left(g_{i}\right)=\frac{1}{1-\tau_{i} \varepsilon_{i}} \forall i
$$

which corresponds to the result derived in the seminal work of Wilson (1986) and Zodrow and Mieszkowski (1986). It is interesting to observe that this result holds regardless of whether individuals are homogeneous or heterogeneous. That is, both (7) and (7-1) will reduce to (7-2) whenever $n \rightarrow \infty$. As $n \rightarrow \infty$, an increase in $t_{i}$ does not change $r$ at all (see Eq. (3-1)), and hence the effect on capital income $r \bar{k}_{i j}$ does not arise. It then follows that the initial distribution of capital holding does not matter for the determination of the tax rate and the level of public goods. 
(iii) $n=1$

Since there is only one region in the economy, this represents the case where there is no tax competition or the economy is closed. Then (7) reduces to

$$
v^{\prime}\left(g_{i}\right)=s_{i j} \forall i
$$

where the elected individual $j$ in region $i$ will choose the public good level that equates the marginal benefit of the public service with his or her share of capital. This result is not surprising since, by the government budget constraint (4), an individual's share of capital determines his or her share of the tax burden in a region in which there is no tax competition (i.e. no mobile tax base).

(iv) $s_{i j}=\theta$ and $n=1$

This is the case where individuals are homogeneous and the economy is closed. Then (7) reduces to

$$
N \cdot v^{\prime}\left(g_{i}\right)=1 \forall i
$$

which is the Samuelson condition for the optimal provision of public goods. Eq. (7-4) uniquely determines the first-best level of public goods, $g^{F}$.

\section{Comparison}

Let us compare standard homogeneous-individual models with our heterogeneousindividual model.

(i) Homogeneity $\left(s_{i j}=\theta\right)$

When $s_{i j}=\theta=1 / N$, (7) will reduce to (7-1), which will further be reduced to (7-4) if and only if $n=1$; that is, when individuals are homogeneous, the level of public goods in a 
region will be optimally supplied if and only if tax competition is absent. ${ }^{10}$ This is the benchmark case considered by most of the tax competition literature. Comparing (7-1) with (7-4) leads to the fundamental result in the literature: tax competition $(n>1)$ results in an undersupply of public goods, relative to the benchmark case where tax competition is absent $(n=1) .^{11}$

(ii) Heterogeneity $\left(s_{i j} \neq \theta\right)$

However, the above fundamental result need not hold in general when there are heterogeneous individuals. First, observe from (7-3) that the level of public goods in the absence of tax competition will be oversupplied rather than undersupplied if $s_{i j}<\theta \equiv 1 / N$, that is, if the elected individual in a region owns a share of capital smaller than the average share in the region. This suggests that tax competition $(n>1)$ may have desirable effects to "correct" the oversupply of public goods in a closed economy $(n=1)$ in the presence of political competition. In the scenario where individuals are homogeneous, we must have $s_{i j}=1 / N$ and there is no political competition by definition. On the contrary, in the scenario where individuals are heterogeneous, we may well have the case of $s_{i j}<1 / N$, so that the consequence of political competition will become important.

Next, when $n \rightarrow \infty$, (7-2) indicates that the level of public goods will be undersupplied, relative to the first-best condition (7-4). By contrast, when $n=1,(7-3)$ indicates that the level of public goods will be oversupplied, relative to the first-best condition (7-4), if $s_{i j}<1 / N$.

Putting together the undersupply if $n \rightarrow \infty$ and the oversupply if $n=1$ suggests the ${ }^{10}$ By our assumptions imposed on $v(),. \tau_{i}>0$ must hold since $\tau_{i}=0$ implies that $g_{i}=0$. It can be seen from (2) that $\partial k_{i} / \partial\left(r+t_{i}\right)=1 / f^{\prime \prime}$ and so $\varepsilon_{i}>0$ must hold as well.

${ }^{11}$ This fundamental result is stated as Proposition 4.1 in Wellisch (2000, p. 64) and as Proposition 4.2 in Haufler (2001, p. 65). 
possibility that there exists an optimal intensity of interregional tax competition, that is, there is an $n=n^{*}$ with $1<n^{*}<\infty$ under which public goods in a region will be optimally supplied.

To sum up, in our heterogeneous-individual model with political competition, tax competition may exert desirable effects on the provision of public goods and, perhaps more interestingly, there may exist an intensity of tax competition to support the optimal level of public goods. We explore both possibilities in Section 4.

\subsection{First stage: political competition}

In this stage, individuals in each region select a policy-maker via election. There are two questions that need be answered. First, who is the decisive voter in selecting a policy-maker? Second, will the decisive voter select him- or herself as the policy-maker or strategically delegate the policy-making to other individuals? We address these two questions in turn.

Decisive voter

From the first-order conditions (6), we have

$$
\frac{\partial\left(\partial u_{i j} / \partial t_{i}\right)}{\partial t_{i}} d t_{i}+\frac{\partial\left(\partial c_{i j} / \partial t_{i}\right)}{\partial \bar{k}_{i j}} d \bar{k}_{i j}=0 \forall i .
$$

From (3) and (5), we have

$$
\frac{\partial c_{i j}}{\partial t_{i}}=-\left(1-\frac{1}{n}\right) \theta k_{i}-\frac{1}{n} \bar{k}_{i j} \forall i .
$$

Suppose the tax rate is raised. Then, the first RHS term of (9) represents the corresponding change in the labor income (the same negative effect across heterogeneous individuals), while the second RHS term of (9) represents the corresponding change in the capital income (varied negative effects across heterogeneous individuals). Both terms are negative.

Since $\partial\left(\partial c_{i j} / \partial t_{i}\right) / \partial \bar{k}_{i j}=-(1 / n)$ by (9), Eq. (8) leads to 


$$
\frac{\partial t_{i}\left(\bar{k}_{i j}\right)}{\partial \bar{k}_{i j}}=\frac{(1 / n)}{\partial^{2} u_{i j} / \partial t_{i}{ }^{2}}<0 \quad \forall i
$$

which implies that the lower the share of capital owned by an individual, the higher is the tax rate preferred by the individual. This result is intuitive because redistribution from the rich to the poor can take place through sharing the cost of the public good provision differently. Nevertheless, the redistributive incentives of the poor are qualified in the presence of tax competition since the RHS of (10) depends on the number of competing regions $n$ as well. In particular, observe that the rich and the poor will concur with each other on the tax policy when $n \rightarrow \infty$. This is so because, from (9), a change in the tax rate will not affect the aftertax rate of return on capital but will only affect the common labor income once $n \rightarrow \infty$.

By the assumption that $\partial^{2} u_{i j} / \partial t_{i}^{2}<0$, the preferences of individuals qua voters exhibit single-peakedness over tax rates $t_{i}$. Since $t_{i}\left(\bar{k}_{i j}\right)$ is monotonic in $\bar{k}_{i j}$ according to (10), the individual preferences for $t_{i}$ induce a preference ordering for $\bar{k}_{i j}$. This induced preference obviously exhibits single-peakedness over capital endowments $\bar{k}_{i j}$. Then, invoking the median voter theorem, we arrive at:

Lemma 1. The lower the share of capital owned by an individual, the higher is the tax rate preferred by the individual. The decisive voter in political competition is the median voter, that is, the individual who owns a median share of $\bar{k}_{i}$, denoted by $s_{i j}^{m}$.

This has a conventional flavor since it agrees with two standard results of political competition: (i) the median voter is a decisive voter in selecting the policy-maker, and (ii) the median voter's income relative to average income is critical in the determination of the size of the public sector as developed by Meltzer and Richard (1981). ${ }^{12}$

\footnotetext{
${ }^{12}$ Fuest and Huber (2001) obtain a similar result with respect to labor income taxation in a tax competition model.
} 


\section{Strategic delegation}

Persson and Tabellini (1992) point out that a decisive voter may not wish to elect him- or herself as the policymaker. ${ }^{13}$ The reason behind this result is that policy-makers evaluate policy ex post (after elections), whereas voters evaluate policy ex ante (before/during elections). In terms of our model, this implies that while the policy-maker in region $i$ takes $t_{-i}$ as given in the second stage of the game (policy-makers move simultaneously in choosing their tax policies according to (6)), voters in region $i$ take the reaction of $t_{-i}$ to $t_{i}$ as given in the first stage of the game (in choosing a policy-maker, voters realize that tax policies will be set according to (6)). Thus, the tax rate preferred by the decisive voter satisfies

$$
\frac{\partial u_{i j}}{\partial t_{i}}+\sum_{-i} \frac{\partial u_{i j}}{\partial t_{-i}} \cdot \frac{\partial t_{-i}}{\partial t_{i}}=0 \quad \forall i
$$

where $u_{i j}$ is evaluated at $s_{i j}^{m}$, the median share of $\bar{k}_{i}$. It is assumed that $\Delta \equiv \partial\left[\partial u_{i j} / \partial t_{i}+\sum_{-i}\left(\partial u_{i j} / \partial t_{-i}\right)\left(\partial t_{-i} / \partial t_{i}\right)\right] / \partial t_{i}<0$ so that the second-order conditions are met and there is a unique $t_{i}\left(s_{i j}^{m}\right)$ satisfying (11).

$$
\begin{aligned}
& \text { Using (3) gives } \\
& \frac{\partial u_{i j}}{\partial t_{-i}}=\frac{1}{n}\left[\bar{k}_{i}\left(\theta-s_{i j}^{m}\right)-\frac{v^{\prime}\left(g_{i}\right) t_{i}}{f^{\prime \prime}}\right] \forall i,-i
\end{aligned}
$$

where we have utilized the property that $k_{i}=\bar{k}_{i}$ in a symmetric Nash equilibrium. Since positively skewed distributions of capital income are typically observed in the real world, we

\footnotetext{
${ }^{13}$ See also Brueckner (2001), who shows that, to offset the tax decreasing (increasing) effect of competition (coordination), the decisive voter has an incentive to elect a policy-maker who has high (low) valuation of public goods. It should be pointed out that the strategic delegation is an interesting rather than essential part of our model. Our main results remain true even if representative democracy (policy is indirectly determined by the decisive voter via the selection of a policy-maker) is replaced by direct democracy (policy is directly determined by the decisive voter).
} 
shall impose the inequality $s_{i j}^{m}<\theta=1 / N$. This then implies from (12) that $\partial u_{i j} / \partial t_{-i}>0$ when it is evaluated at $s_{i j}^{m}$.

As long as $\partial t_{-i} / \partial t_{i}>0$, which is reasonable in the context of tax competition and particularly true in our symmetric model, (11) and the positive sign of (12) together yield: $\partial u_{i j} / \partial t_{i}<0$ when it is evaluated at $s_{i j}^{m}$. Appealing to (10), $\partial u_{i j} / \partial t_{i}<0$ at $s_{i j}^{m}$ plus $\partial^{2} u_{i j} / \partial t_{i}^{2}<0$ then implies:

Lemma 2. The decisive median voter in each region will select a policy-maker whose capital share is lower than $s_{i j}^{m}$ if $n>1$, but will select him- or herself as the policy-maker if $n=1$.

That is to say, when $n>1$, the decisive voter will not select him- or herself as the policymaker but will strategically delegate the policy-making to other individuals whose capital share is lower than his or her own share $s_{i j}^{m}$. The intuition is as follows. The tax rate preferred by the decisive voter satisfies (11), which is the optimal condition ex ante (before/during elections). By contrast, the tax rate preferred by the policy-maker satisfies (6), which is the optimal condition ex post (after elections). The optimal ex ante tax rate is higher than the optimal ex post tax rate, since $\partial u_{i j} / \partial t_{i}<0$ at the ex ante optimum whereas $\partial u_{i j} / \partial t_{i}=0$ at the ex post optimum. To implement the higher optimal ex ante tax rate, the selected policy-maker must have a lower capital share than the median voter (see Eq. (10)). This outcome results simply because the decisive voter takes the reaction of $t_{-i}$ to $t_{i}$ as given, while the policy-maker takes $t_{-i}$ as given. Anticipating an increase in $t_{i}$ will induce an increase in $t_{-i}$, the decisive voter is better off via delegating the policy-making to an individual with a capital share lower than his or her own. 
When $n=1$, (11) will collapse to (6) since $-i$ does not exist. In such a case, it is obvious that the decisive voter will select him- or herself as the policy-maker and there is no strategic delegation.

The decisive voter takes the reaction of $t_{-i}$ to $t_{i}$ as given. From (11), we then have

$$
\Delta d t_{i}+\left[\frac{\partial\left(\partial c_{i j} / \partial t_{i}\right)}{\partial \bar{k}_{i j}}+\sum_{-i} \frac{\partial\left(\partial c_{i j} / \partial t_{-i}\right)}{\partial \bar{k}_{i j}} \cdot \frac{\partial t_{-i}}{\partial t_{i}}\right] d \bar{k}_{i j}=0 \quad \forall i .
$$

Since $\partial\left(\partial c_{i j} / \partial t_{i}\right) / \partial \bar{k}_{i j}=\partial\left(\partial c_{i j} / \partial t_{-i}\right) / \partial \bar{k}_{i j}=-(1 / n),(13)$ leads to

$$
\frac{\partial t_{i}\left(s_{i j}^{m}\right)}{\partial \bar{k}_{i j}^{m}}=\frac{(1 / n)+\sum_{-i}(1 / n)\left(\partial t_{-i} / \partial t_{i}\right)}{\Delta}<0 \forall i
$$

where $\bar{k}_{i j}^{m}=s_{i j}^{m} \cdot \bar{k}_{i}$. Let $s_{i j}^{p}$ denote the share of capital owned by the policy-maker, who is selected by the decisive median voter with $s_{i j}=s_{i j}^{m}$. Putting (10) and (14) together yields:

Lemma 3. The lower the $s_{i j}^{m}$, the lower is the $s_{i j}^{P}$.

In words, the lower the share of capital owned by a decisive voter, the higher is the tax rate preferred by the decisive voter (see Eq. (14)); as a result, the decisive voter will select a policy-maker who has a lower share of capital to implement the decisive voter's preferred tax rate (see Eq. (10)).

\section{Implications of tax-cum-political competition}

This section explores the implications of the interaction between interregional tax competition and intraregional political competition for the provision of public goods.

\subsection{Preliminary analysis}


From the first-order conditions (6), we obtain ${ }^{14}$

$$
\frac{\partial\left(\partial u_{i j} / \partial t_{i}\right)}{\partial t_{i}} d t_{i}+\left[\frac{\partial\left(\partial c_{i j} / \partial t_{i}\right)}{\partial n}+v^{\prime}\left(g_{i}\right) \frac{\partial\left(\partial g_{i} / \partial t_{i}\right)}{\partial n}\right] d n=0 \quad \forall i \text {. }
$$

Note that $\partial\left(\partial c_{i j} / \partial t_{i}\right) / \partial n=\left(1 / n^{2}\right)\left(\bar{k}_{i j}-\theta k_{i}\right)$ and that $\partial\left(\partial g_{i} / \partial t_{i}\right) / \partial n=\left(1 / n^{2}\right)\left(t_{i} / f^{\prime \prime}\right)$ by (3)-(5), and hence Eq. ( 15) leads to

$$
\frac{\partial t_{i}\left(\bar{k}_{i j}\right)}{\partial n}=\frac{\left(1 / n^{2}\right)\left[\left(\theta \bar{k}_{i}-\bar{k}_{i j}-v^{\prime}\left(g_{i}\right)\left(t_{i} / f^{\prime \prime}\right)\right]\right.}{\partial^{2} u_{i j} / \partial t_{i}^{2}} \forall i
$$

where we utilize $k_{i}=\bar{k}_{i}$ in a symmetric Nash equilibrium. This result implies that $\left(\partial t_{i}\left(\bar{k}_{i j}\right) / \partial n\right)<0$ if $\bar{k}_{i j}<\theta \bar{k}_{i}$; that is, the equilibrium tax rate chosen by the policy-maker is monotonically decreasing in the number of competing regions if $s_{i j}<1 / N$. From Lemma 2, the decisive median voter selects a policy-maker who owns a capital share $s_{i j}^{P}$ equal to or lower than the median share $s_{i j}^{m}$, which is lower than the mean share $1 / N$. Thus, we have:

Lemma 4. $\left(\partial t_{i}\left(\bar{k}_{i j}\right) / \partial n\right)<0$ holds in equilibrium in our economy.

Eq. (9) gives $\left(\partial c_{i j} / \partial t_{i}\right)=-\bar{k}_{i}\left[\theta(1-(1 / n))+(1 / n) s_{i j}\right]<0$ in equilibrium. Thus, from (6), we also have:

Lemma 5. $\left(\partial g_{i} / \partial t_{i}\right)>0$ holds in equilibrium in our economy.

With Lemmas 1-5 at hand, we now turn to the two possibilities mentioned in Section 3: the desirable effects of tax competition and the optimal intensity of tax competition. For ease of exposition in the following, we employ the terms "increased" interregional tax competition and "increased" intraregional political competition. We first explain what they mean.

\footnotetext{
${ }^{14}$ We treat $n$ as a continuous variable as in Seade (1980).
} 
The term "increased interregional tax competition" simply means an increase in the number of competing regions $n$. This follows Wilson and Widasin (2004).

Following Meltzer and Richard (1981), we view the deviation between $s_{i j}^{m}$ (the median share of capital) and $1 / N$ (the mean share of capital) as a metaphor for income inequality in a region. The larger the deviation between $s_{i j}^{m}$ and $1 / N$, the higher is the degree of income inequality in the region. Given $1 / N$, we interpret a decrease in $s_{i j}^{m}$ (a deterioration in income inequality) as "increased” intraregional political competition, in the sense that the interest conflict between the mean and the median voter increases.

\subsection{Optimal interregional tax competition}

When there is no tax competition or the economy is closed (i.e., $n=1$ ), we have in equilibrium

$$
v^{\prime}\left(g_{i}\right)=s_{i j}^{m} \forall i
$$

where we have utilized Lemmas 1-2. Eq. (7-3*) implies that $N \cdot v^{\prime}\left(g_{i}\right)<1$ in equilibrium since $s_{i j}^{m}<(1 / N)$.

When $n \rightarrow \infty$, (7-2) indicates that the level of public goods in a region will be undersupplied, relative to the first-best condition (7-4). This outcome results because the force of tax competition completely dominates when $n \rightarrow \infty$. By contrast, when $n=1$, (7$3^{*}$ ) indicates that the level of public goods in a region will be oversupplied, relative to the first-best condition (7-4). This outcome results because the force of political competition completely dominates when $n=1$. Putting them together and appealing to Lemmas 4-5, one would conjecture that there exists an $n=n^{*}$ with $1<n^{*}<\infty$ under which public goods in a region will be optimally supplied. This conjecture is verified below. 
Replacing $s_{i j}$ with $s_{i j}^{P}$ in Eq. (7) and solving for $n$ that satisfies the first-best condition $N \cdot v^{\prime}\left(g_{i}\right)=1$ leads to

$$
n^{*}=1+\frac{1-N s_{i j}^{p}}{\tau_{i} \varepsilon_{i}} \forall i .
$$

This resulting $n^{*}$ will be greater than 1 but smaller than infinity if the inequality $s_{i j}^{P}<1 / N$ holds. ${ }^{15}$ By Lemmas 1-2, we indeed have $s_{i j}^{P} \leq s_{i j}^{m}<1 / N$ in equilibrium.

To sum up, we obtain

Proposition 1-T (Tax competition). Given $s_{i j}^{m}<(1 / N)$ (intraregional political competition), there is an $n=n^{*}\left(s_{i j}^{m}\right)$ (the optimal interregional tax competition) with $1<n^{*}\left(s_{i j}^{m}\right)<\infty$ under which public goods will be optimally supplied $\left(g_{i}=g^{F}\right)$.

Mathematically, $n=1$ must hold if one wants to reduce (7-1) to (7-4). In other words, to achieve the first-best provision of public goods in an economy with homogeneous individuals, there must be no tax competition. This leads to the fundamental result in the literature that tax competition ( $n>1)$ will result in an undersupply of public goods (relative to the first-best in a closed economy). By contrast, we have shown that it is possible to reduce (7) to (7-4) with $n>1$ in our heterogeneous-individual economy when political competition is present.

Proposition 1 immediately leads to:

\footnotetext{
${ }^{15}$ The case where $\tau_{i} \varepsilon_{i} \rightarrow 0$ is ruled out by default, otherwise (7-1) would reach the first-best regardless of $n$.
} 
Corollary 1-T. Given $s_{i j}^{m}<(1 / N)$, increased interregional tax competition (an increase in $n$ ) will "correct" the oversupply of public goods caused by intraregional political competition if $n<n^{*}\left(s_{i j}^{m}\right)$.

By Lemma 3, we know that $d s_{i j}^{P} / d s_{i j}^{m}>0$, that is, $s_{i j}^{P}$ is a strictly increasing function of $s_{i j}^{m}$. Thus, (17) gives the following characterization for $n^{*}\left(s_{i j}^{m}\right)$.

Proposition 2-T. Other things being equal (i.e., $N$ and $\tau_{i} \varepsilon_{i}$ are given), the lower the $s_{i j}^{m}$, the higher will be the optimal tax competition $n^{*}\left(s_{i j}^{m}\right)$.

The policy implication of Proposition 2-T is that the higher the income inequality in a region, the higher is the oversupply of public goods from intraregional political competition in the region and, therefore, the higher the optimal interregional tax competition that will be required to achieve the first-best provision of public goods.

\subsection{Optimal intraregional political competition}

Replacing $n^{*}$ with an arbitrary $n$, there is an $s_{i j}^{P}=s_{i j}^{P^{*}}$ that satisfies (17). From Lemmas 1-2, this $s_{i j}^{P^{*}}$ is selected by the decisive voter with $s_{i j}^{m}=s_{i j}^{m^{*}}$ via intraregional political competition. Thus, Proposition 1-T can be put differently:

Proposition 1-P (Political competition). Given $n>1$ (interregional tax competition), there is an $s_{i j}^{m}=s_{i j}^{m^{*}}(n)$ (the optimal intraregional political competition) under which public goods will be optimally supplied $\left(g_{i}=g^{F}\right)$.

Corollary 1-T can also be put differently: 
Corollary 1-P. Given $n>1$, increased intraregional political competition (a decrease in $s_{i j}^{m}$ )

will "correct" the undersupply of public goods caused by interregional tax competition if $s_{i j}^{m}>s_{i j}^{m^{*}}(n)$.

Using (17), we obtain

$$
N s_{i j}^{P^{*}}=1-(n-1) \tau_{i} \varepsilon_{i} \forall i \text {. }
$$

Because $d s_{i j}^{P} / d s_{i j}^{m}>0$ from Lemma 3, we have the following characterization for $s_{i j}^{m^{*}}(n)$.

Proposition 2-P. Other things being equal (i.e., $N$ and $\tau_{i} \varepsilon_{i}$ are given), the higher the $n$, the lower will be the optimal intraregional political competition $s_{i j}^{m^{*}}(n)$.

The policy implication of Proposition 2-P is that the higher the interregional tax competition facing a region, the higher is the undersupply of public goods in the region and, therefore, the higher the income inequality that will be required for intraregional political competition to achieve the first-best provision of public goods.

\section{Conclusion}

This paper has explored the implications of the interaction between interregional tax competition and intraregional political competition for the optimal provision of public goods. In contrast to Hoyt's (1991) finding that the extent to which public goods are undersupplied is monotonically increasing in the number of competing regions, we have shown that the relationship between the level of public good supply and the number of competing regions is non-monotonic if political as well as tax competition is considered. Interestingly, we have found that interregional tax competition alone tends to lead to an undersupply of public goods, while intraregional political competition alone tends to lead to an oversupply of public goods; 
however, putting both competitions together can result in the optimal provision of public goods. In this sense, considering either competition in isolation is indeed incomplete, if not misleading.

In the presence of political competition, tax competition may have desirable effects and, perhaps more interestingly, there may be an optimal intensity of tax competition. Our result suggests that Hoyt's (1991) emphasized tradeoff between Tiebout sorting and the costs of tax competition may not exist once political as well as tax competition is considered.

Our model is admittedly highly stylized and abstracts from several possible directions of generalization, such as asymmetric country size, heterogeneous non-capital income, incumbency effects, the role of bureaucrats, and taxes other than the capital income tax. Nevertheless, it is hoped that our model may have highlighted the importance of considering both tax and political competition in the analysis of public good provision. 


\section{References}

Batina, R.G., T. Ihori, 2005. Public Goods: Theories and Evidence. Springer-Verlag, Berlin.

Besley, T., S. Coate, 1997. An economic model of representative democracy. Quarterly Journal of Economics 112, 85-114.

Besley, T., S. Coate, 2003. Centralized versus decentralized provision of local public goods: a political economy approach. Journal of Public Economics 87, 2611-2637.

Brueckner, M., 2001. Strategic delegation and international capital taxation. Manuscript, University of Bonn.

Edwards, J., M. Keen, 1996. Tax competition and Leviathan. European Economic Review 40, 113-134.

Frey, B., Eichenberger, R., 1996. To harmonize or to compete? That is not the question. Journal of Public Economics 60, 335-349.

Fuest, C., Huber, B., 2001. Tax competition and tax coordination in a median voter model. Public Choice 107, 97-113.

Fuest, C., Huber, B., J. Mintz, 2005. Capital mobility and tax competition. Foundations and Trends in Microeconomics 1, 1-62.

Haufler, A., 2001. Taxation in a Global Economy. Cambridge University Press, Cambridge.

Hoyt, W.H., 1991. Property taxation, Nash equilibrium, and market power. Journal of Urban Economics 30, 123-131.

Meltzer, A., S. Richard, 1981. A rational theory of the size of government. Journal of Political Economy 89, 914-927.

Oates, W.E., 1972. Fiscal Federalism, Harcourt Brace Jovanovich, New York.

Osborne, M.J., A. Slivinski, 1996. A model of political competition with citizen candidates. Quarterly Journal of Economics 111, 65-96.

Persson, T., G., Tabellini, 1992. The politics of 1992: fiscal policy and European integration. Review of Economic Studies 59, 689-701. 
Rauscher, M., 1998. Leviathan and competition among jurisdictions: the case of benefit taxation. Journal of Urban Economics 44, 59-67.

Seade, J., 1980, On the effects of entry. Econometrica 48, 479-489.

Varian, H.R., 1992. Microeconomic Analysis, Third Edition. Norton \& Company, New York.

Wellisch, D., 2000. Theory of Public Finance in a Federal State. Cambridge University Press, Cambridge.

Wildasin, D.E., 1988. Nash equilibrium in models of fiscal competition. Journal of Public Economics 35, 229-240.

Wilson, J.D., 1986. A theory of interregional tax competition. Journal of Urban Economics 19, 296-315.

Wilson, J.D., 1999. Theories of tax competition. National Tax Journal 52, 269-304.

Wilson, J.D., 2005. Welfare-improving competition for mobile capital. Journal of Urban Economics 57, 1-18.

Wilson, J.D., D.E. Wildasin, 2004. Capital tax competition: bane or boon. Journal of Public Economics 88, 1065-1091.

Zodrow, G.R., P.M. Mieszkowski, 1986. Pigou, Tiebout, property taxation, and the underprovision of public goods. Journal of Urban Economics 19, 356-370. 